Revista Iberoamericana, Vol. LXXIII, Núm. 218, enero-marzo 2007, 69-77

\title{
LA (POS)MODERNA TENOCHTITLAN: NOTAS SOBRE LA CIUDAD EN MATERIA DISPUESTA DE JUAN VILLORO
}

\author{
POR \\ SARISSA CARNEIRO ${ }^{1}$ \\ Pontificia Universidad Católica de Chile
}

$\mathrm{Si}$, en distintos momentos de la historia, la ciudad fue el símbolo del orden, la perfección, la civilización y la modernidad, es decir: la realización de un diseño buscado como Ciudad Ideal, las megalópolis latinoamericanas actuales son, en muchos aspectos, un contratexto de dicha idealidad. Esta afirmación supone una paradoja o la ironía de un destino ya que, desde su "descubrimiento", América Latina fue pensada como espacio de realización de utopías además de encuentro con tierras míticas.

Ángel Rama calificó a la ciudad latinoamericana de "parto de la inteligencia”, cumplimiento del sueño del orden, sueño que sólo podría realizarse en las tierras "vírgenes" del Nuevo Mundo, un edificio ex-nihilo hecho a la medida de una nueva época (2). El diseño en damero, característico de las ciudades latinoamericanas, más que una distribución geométrica, sería la transposición de un orden social jerárquico; la unidad, la planificación y el orden riguroso obedecerían, entonces, a un régimen de trasmisiones: “de lo alto a lo bajo, de España a América, de la cabeza del poder ... a la conformación física de la ciudad” (8).

Ciudad de México, la ciudad más grande del mundo, concentra hoy, en su cartografía huidiza, en su mancha urbana, todos los excesos posibles: un crecimiento desconcertante, un cielo gris, una población de aproximadamente veinte millones de habitantes, desperdicios suficientes para llenar cada día sus recintos más grandes. Algunos problemas recientes como el deterioro de sus espacios públicos, el crecimiento descontrolado, la violencia segregante (García Canclini, 1999) se suman a dificultades antiguas y persistentes: la lucha contra las condiciones naturales, geográficas y climáticas, y una organización sociopolítica que supone privilegios y exclusiones (González Rodríguez).

Juan Villoro (México, 1956) entiende la ciudad de México como "un territorio que excede la experiencia humana”; su ciudad natal sería lo inabordable, "un palimpsesto mil veces corregido", "un caos que nos rebasa a diario con frenética intensidad” "Los días robados: cielo artificial”). Las novelas, cuentos y crónicas de este escritor pueden ser vistos como una reinvención territorial del Distrito Federal y participan, así, de una tendencia de la actual narrativa mexicana que intenta inventarle un sentido a esta ciudad (“Entrevista con Juan Villoro” 119).

${ }^{1}$ Con el apoyo de CONICYT, Beca Doctorado. 
La presente nota aborda esa invención territorial en Materia dispuesta, segunda novela de Juan Villoro. Aquí, Mauricio Guardiola, el protagonista/ testigo, deambula por la ciudad recogiendo de ella, como "materia dispuesta", los signos urbanos que puedan contribuir a armar una identidad en el momento crítico que vive, el paso de la niñez a la adolescencia y a la vida adulta. Su desorientación, el abandono de referentes que padece no pueden ser contrarrestados por una ciudad-Nación que ofrece solo fragmentos y desechos comparables a su “colección de basuras”, lo que hace de esta obra un irónico reverso de la novela de educación sentimental y de aprendizaje.

Ciudad, cuerpo y nación son las tres zonas que, en la línea de los estudios culturales, pretendo considerar en este artículo. ${ }^{2}$ Así, en la primera parte, examino la dinámica centroperiferia, los poderes implícitos en el texto urbano, los privilegios y exclusiones de una cartografía en permanente transformación. El segundo apartado se aproxima, por su parte, a las remodelizaciones imaginarias de un sujeto que, en su devenir identitario, cuestiona la masculinidad hegemónica y establece una relación original con el espacio urbano. Por último, la tercera parte se centra en el problema de la Nación: el desmoronamiento de los valores establecidos respecto de la identidad nacional, la agonía del sistema autoritario, la transformación de las tradiciones en mercancías adaptadas al turismo o al exotismo.

Terminal Progreso: LA ORILla DE LA NADA

En oposición a la ciudad tradicional-ciudad con un centro definido, con monumentos, plazas, teatros, cines, cruces de calles importantes- la ciudad actual, posmoderna, sería una ciudad sin centro, una ciudad fragmentaria y dispersa donde el espacio público privatizado altera los tradicionales espacios urbanos con nuevas tipologías arquitectónicas (Pérgolis 3) o una ciudad diseminada, sin límites precisos, donde difícilmente se puede tener una experiencia de conjunto (García Canclini, Globalización imaginada 82).

Como señala Jameson, el hiperespacio posmoderno lleva a la ruptura entre cuerpo y espacio urbano exterior pues "ha conseguido trascender definitivamente la capacidad del cuerpo humano individual para autoubicarse, para organizar perceptivamente el espacio de sus mediaciones, y para cartografiar cognitivamente su posición en un mundo exterior representable” (97). Esa dificultad proviene, según Jameson, de la incapacidad para confeccionar el mapa de la red comunicacional descentrada, multinacional y global en que estamos atrapados actualmente.

Bernardo Subercaseaux resume este fenómeno llamado globalización o mundialización en los siguientes términos: libre circulación de bienes de flujos financieros y bienes económicos, expansión de la lógica del mercado a casi todo el planeta, desarrollo incesante de nuevas tecnologías de comunicación e información que rompen los tradicionales

\footnotetext{
${ }^{2}$ Mi perspectiva se aparta, por lo tanto, de una aproximación anterior al mismo tema. Jesús Eduardo García Castillo, en su trabajo, “Alegorías de tiempo y espacio en Materia dispuesta y El miedo a los animales” también aborda la ciudad en la novela de Villoro. Su lectura, sin embargo, es muy distinta a la mía. García Castillo analiza los diferentes cronotopos de la novela utilizando, para el cronotopo diegético, los conceptos greimasianos de espacio tópico, paratópico y utópico; relaciona, asimismo, los efectos estilísticos y temáticos de la novela como marcas finiseculares que dan cuenta de las reacciones de su autor al entorno.
} 
conceptos de tiempo y espacio, transnacionalización de los procesos históricos, pérdida de la soberanía (especialmente económica) de los estados nacionales, liberalización de los mercados, creación de pactos o bloques regionales (9). En el plano social, sin embargo, señala Subercaseaux que la globalización convive con "lógicas de desigualdad y con una persistencia de la pobreza y la desintegración social, sobre todo en África y América Latina” (10). Del mismo modo, en el ámbito cultural, la idiosincrasia de lo local y lo nacional se ve afectada por el "predominio de la massmediatización, la internacionalización y la organización audiovisual de la cultura” (11).

En plena era globalizada y descentrada, Materia dispuesta invita a mirar la orilla, el borde, la periferia, “Terminal Progreso” entre los años 60 y 80. Así, más que un simple hacer memoria del pasado, Villoro pareciera estar preguntándonos hasta qué punto las ciudades latinoamericanas son ciudades globales y en qué medida se ha desvanecido la jerarquía centro-periferia en nuestro paisaje urbano o en la aldea global de la que se supone somos parte.

Frente al problema de la desterritorialización, Renato Ortiz propone una nueva configuración del espacio como conjunto de planos atravesados por líneas de fuerza con tres dimensiones simultáneas, las historias locales, las historias nacionales y la mundialización, todas existentes en la medida en que son vivencias de lo cotidiano (62). La vivencia de Mauricio, en su niñez y adolescencia, es la de vivir en el límite de la ciudad, en la "orilla de la nada” (31), “en la espera del rescate” (38), en un "planeta abandonado”, "borde nunca rebasado de la ciudad” (29), lugar de los desechos.

En la línea de Deleuze podríamos decir que si hoy, Terminal Progreso, el límite, desapareció, fue para seguir existiendo: "tal es la simultaneidad de un devenir cuya propiedad es esquivar el presente” (25), "identidad infinita de los dos sentidos a la vez, del futuro y del pasado, de la víspera y el día después” (26).

Su mismo nombre encierra ya una contradicción, Terminal Progreso, la última estación del tranvía, es donde termina, pero también hasta donde llega el progreso y la modernidad. Desde allá, a "medio camino entre el feudalismo y la primera industria" (180), Mauricio escucha la ciudad vibrando, eléctrica (28) en vertiginoso crecimiento.

Aquí cobra enorme importancia lo telúrico. La naturaleza recuerda, como diría Villoro en “Días robados: El cielo artificial”, que de Tenochtitlan al Distrito Federal hay un "palimpsesto mil veces corregido, borradores que ya olvidaron su modelo original y jamás darán una versión definitiva” (1). El paisaje combina tiempos que no se cancelan y si a Terminal Progreso llega el tranvía llegan también los ajolotes y las obsidianas (cronómetros infinitos) que recuerdan "volcanes activos y saurios fabulosos" en "el agua castigada de Xochimilco”, lo único que quedaba del lago de los aztecas (29).

La obsesión de Mauricio por los ajolotes podría estar hablando de la importancia de lo híbrido o lo anfibio en la novela. Ajolote y salamandra, ciudad y campo, niño y hombre, épocas/identidades que no se cancelan pues son pasado y futuro en la eterna huida del presente. Cito un pasaje iluminador en ese sentido: “Aquel paraje era un híbrido sin gloria; la ciudad sitiaba al campo sin derrotarlo y llegaba a nosotros en forma precaria: en los riachuelos, los celofanes de golosinas devoradas desde hacía varios meses flotaban junto a los lirios” (29). 
Terminal Progreso es también el contratexto de las ciudades ideales que persiguen los personajes de la novela. Colonia Roma, el barrio abandonado por la familia Guardiola en la diáspora que sucedió al terremoto de 1957, es, para la madre de Mauricio el recuerdo de una época áurea. Deja, curiosamente, de pertenecer a la ciudad de México y pasa a identificarse con la tierra clásica:

Se diría que en otro tiempo vivimos junto a la columna de Trajano, a orillas del Tíber, rodeados de las siete colinas de fábula. "Roma” era el nombre, eterno y convulso, del sitio que perdimos. Las depresiones de mamá lograron que una zona que en el mejor de los casos aspiraba a ciertos triunfos art nouveau, se transformara en tierra clásica. (32)

Junto a Roma, París y Venecia configuran el cuadro de ciudades ideales o “verdaderas"(33). La antigua Tenochtitlan, mil veces comparada con Venecia, entró en desgracia cuando secó sus aguas y dejó de parecerse a su involuntario modelo. París, otra ciudad ideal, es parte clave del imaginario urbano de Mauricio y su familia: en la sala de la casa, colgado por el padre, un mapa de París a vuelo de pájaro lo recuerda a cada instante.

Como contratexto, la periferia recuerda la persistencia de las desigualdades sociales. Xochimilco, después de tantos años abandonado, podría transformarse en “jardín regulado” para evitar la invasión impulsada por el aumento de los precios de las tierras y el crecimiento de la población urbana. El subsecretario de Obras Públicas, Gutiérrez Pool, encarga al padre de Mauricio la construcción de ese "jardín regulado” cuyo objetivo sería entregar a la ciudad un "símbolo nítido del poder que la controla" (237). Si el proyecto fracasa es porque la ciudad subterránea cobra su venganza, la excavación descubre un posible cementerio azteca y Xochimilco se transforma en "bastión del mundo mesoamericano" (260).

En cuestiones de poder, la tierra recuerda, repetidas veces, que el de los hombres no es ilimitado. La construcción infatigable de esos fantasmas albañiles, "esclavos de las construcciones que modifican la ciudad" (107), se hace pedazos en pocos minutos con los movimientos de la tierra. Mauricio percibe esa lógica de la naturaleza y ordena su relato/ vida a partir de los terremotos que experimenta: el primero, de 1957, año de su nacimiento, obliga a la familia a abandonar su casa y provoca la caída del Ángel de la Independencia; el segundo ocasiona una escena primaria, cuando ve al padre con Rita, una amante; el último, de 1985, le depara una nueva epifanía, el encuentro amoroso con Verónica, el valor de recoger lo disperso y lo roto, el "borde de las cosas" (311). Sin embargo, más que la naturaleza, es sobre todo la ciudad la que entra en una relación de flujos continuos con el sujeto.

Mauricio en el Borde de LAS COSAs: SUJeto y CIUdAd

Al rechazar el modelo de masculinidad hegemónica, Mauricio se apropia del espacio urbano en un sentido no falogocéntrico. Con esta afirmación, recojo la idea de que espacio y género, como señala María Inés García, “se entrelazan siendo imposible su separación: los cuerpos en su devenir requieren de un espacio de existencia, espacio que les da su sello 
y su marca y, al mismo tiempo, esos cuerpos construyen la historia del suelo que habitan” (49).

Al principio de su narración autobiográfica, Mauricio asocia el recuerdo del padre con el lado rasposo de la toalla. La furia con que Jesús Guardiola frotaba su cuerpo, la satisfacción que le provocaban sus músculos y el particular código de valores espartanos que profesaba sugerían al niño un modelo de virilidad no imitable. Así, dice haber crecido "del lado opuesto" (15), más cerca de lo femenino que de lo varonil: "Supongo que me seguí bañando porque mamá suavizaba toallas secretas para ella y para mí... algo que en la esotérica valoración de las telas familiares significaba dejarse llevar por la vida fácil, ceder a las presiones y a los gustos plácidos” (15).

En este aspecto, Mauricio se asemeja a sus ajolotes. El padre le advierte que los ajolotes podían mutar en salamandras “pero no todos sino los escogidos” (85). De alguna manera, transformarse en hombre también es algo para “escogidos” en un régimen estricto de la masculinidad mexicana. El ajolote, entre lo primitivo y fetal, estaría, además, significando lo anterior al nombre del padre y el orden simbólico de carácter falogocéntrico. Así, los ajolotes de Mauricio estarían dando cuenta de su carácter difuso en términos genéricos.

Mauricio oscila entre el deseo homoerótico y el heterosexual sin preocuparse, en ningún momento, por “el sentido común como asignación de identidades fijas” (Deleuze, 27). Su despertar sexual está marcado por la figura del vulcanizador, “su recubrimiento de carbón, su aspecto fabuloso, escapado de un comic, de los planetas donde los guerreros usaban mallas” (27). De la cultura mediática proviene también el otro cuerpo que excita a Mauricio en su infancia y adolescencia, el cuerpo victimizado de Superman (54), y la posterior afición por la iconografía católica se explica en la medida en que le recordaba "la narrativa en cuadros de las historietas" (74).

Si hay algo que conecta a estos cuerpos masculinos deseados con las mujeres con que Mauricio se relaciona después (Regina, Lorena y Verónica) es su condición de belleza castigada. Superman, como San Andrés, excita en la medida en que es un héroe victimizado, una potencia castigada (54). Lo mismo ocurre con las mujeres y en eso vuelve a apartase del modelo paterno falogocéntrico: “Comparaba con cuidado a las amantes de mi padre pero no sentía atracción por ellas. Mi idea de belleza femenina tenía que ver con el sufrimiento. Los ojos de Verónica eran maravillosamente tristes...” (23). Demás está decir que esto se contrapone también a la actual sociedad posmoderna de ingeniería corporal que une los mitos de belleza y juventud de acuerdo al design del mercado.

En entrevista con Ángel Jaramillo Torres, Villoro se refiere a esa belleza vulnerable, y explica que "la percepción física se humaniza con algún defecto, con algún padecimiento, con alguna dolencia” pues "nos podemos vincular con la gente mucho mejor por sus heridas”. No es de extrañar, entonces, que en ese contexto la ciudad de México sea, para el escritor, "la mujer barbuda del circo, que no es la más hermosa del mundo pero, pues necesitas los besos con barba y bigote que sólo ella te puede dar" ("Mudarse para mejorarse”, entrevista de Alberto Sánchez).

La identidad de Mauricio es un continuo devenir de flujos cuya única constante es recoger fragmentos borrando sus vínculos. Si en lo sexual permanece en la ambigüedad, tampoco se preocupa de vincularse con una profesión que le confiera una identidad laboral 
estable. Deambulando por la ciudad, llega a ser taxista, camarógrafo y brigadista con el único criterio de la coincidencia o el azar.

El final de la novela presenta una nueva reflexión sobre las "toallas ejemplares". Mauricio comprende, entonces, la diferencia entre secarse con el lado rasposo o con el lado suave de la toalla:

\footnotetext{
Mauricio sintió que todo encajaba de otro modo ... pensó que para su padre la Calle del Oro hubiera sido un tema de reconstrucción, un motivo ideal para subir materia. Lo vio ante el espejo, frotándose la espalda con furia, y en la profusión de las cosas sueltas, del cascajo, de lo que reposaba sin autoridad, Mauricio entendió lo que significaba el otro lado de la toalla: podía dividirlo todo a la manera de las toallas: el lado áspero para quienes construían y se adelantaban al destino; el lado suave para los testigos que recogían las porciones dispersas, rotas... (311)
}

Considero que esa identidad en constante devenir del testigo que recoge lo disperso nos está hablando también de un modo particular de relacionarse con (e incidir en) el espacio urbano. Los que, como el arquitecto Guardiola, se adelantan al destino, pretenden "subir materia”, construir, someter y apropiarse. El gesto de Mauricio propone otra territorialidad; su colección de basuras atrae el borde de las cosas. Sin embargo, no por ello es ajeno a cierta creación: recoger los trozos sueltos, los guijarros, las esquirlas de los demás, según Villoro, está muy cerca de la función de la literatura y, por lo tanto, del arte (Entrevista de Ignacio Echevarría).

\section{LOS FRAGMENTOS DE LA NACIÓN}

La puesta en crisis de los valores sexuales hegemónicos y de la construcción falologocéntrica del espacio urbano se suman, en la novela de Villoro, al desmoronamiento de la Nación. No se trata simplemente de una crisis de lo local o nacional como (supuesta) homogeneidad penetrada por una mundialización que atrae lo foráneo, heterogéneo e híbrido sino a un poner en cuestionamiento la existencia misma de una identidad nacional, de una autenticidad que remita a un origen. Materia dispuesta se refiere sobre todo a México, pero al hacerlo, entra al tan convulso como extenso debate sobre la identidad latinoamericana.

En el momento actual, definido por Hardt y Negri como Imperio (nueva forma de soberanía compuesta por una serie de organismos nacionales y supranacionales unidos por una lógica de dominio), el Estado Nación tiene cada vez menos poder para regular los flujos no sólo económicos sino también culturales (13-14). Frente a esta situación, algunos se han preocupado de reivindicar la idea nacional y la diferencia. Me permito poner un ejemplo de Chile. Bernardo Subercaseux, al abordar el problema de la nación y la cultura en América Latina, entiende que el espesor cultural de origen étnico y demográfico, base de la diversidad cultural del continente, "tiene una función de argamasa: constituye a la vez un fenómeno de cohesión social y de apelación identitaria” (16). Desde esa perspectiva, algunos procesos homogeneizadores de la globalización tienen efectos "negativos” y "preocupantes para la supervivencia y desarrollo del espesor cultural local” (17). 
Pienso que la postura que asume Villoro en relación con este tema queda muy clara en su texto “Mexicamérica: la frontera de los ilegales”. Allí el escritor señala que tanto las 56 lenguas indígenas que se hablan en el territorio mexicano, como la Iglesia Católica y los "yuppies" que creyeron que el Tratado de Libre Comercio sería un "programa de viajero frecuente al Primer Mundo” son identidades, todas ellas mexicanas y también todas ellas provisionales. Para Villoro, "resulta ocioso buscar el rostro primigenio e inmutable", "la identidad unívoca, distinguible, que nos separa del resto de los hombres" porque los múltiples rostros de México, sus múltiples máscaras, invitan a una "concepción pulverizada, dispersa, múltiple, híbrida, de la identidad” (“Méxicamérica...”).

Esta posición no es, sin embargo, celebratoria de la homogeneización sino crítica de una tendencia a ubicar lo supuestamente auténtico (lo indígena, lo negro, lo popular, etc) en el pasado para evitar el abordarlo como problema actual. La idealización del mundo precolombino "relega el tema indígena a una arcadia perdida”, "los indios no son: fueron” (“Chiapas: el regreso de los intocables”).

En ese aspecto, Villoro se acerca a algunos autores latinoamericanos como Jesús Martín-Barbero o García Canclini. Este último, en Culturas híbridas critica la Carta del Folclor Americano, donde se entiende lo indígena como lo siempre inalterable, lo esencial de la identidad y el patrimonio cultural de cada país (199). Martín-Barbero, por su parte, en De los medios a las mediaciones rechaza el nacionalismo populista "obsesionado con el 'rescate de las raíces' y la pérdida de la identidad, una identidad a buscar por supuesto en el mundo indígena rural” (205).

En Materia dispuesta, el “argumento azteca” aparece como comodín útil para distintos poderes que ocultan, en realidad, otros intereses que poco tienen que ver con el rescate de la autenticidad. En relación con el "jardín regulado”, se cuestionan diversos aspectos como el concepto de patriotismo, la relación del mexicano con su cultura, el interés de los organismos supranacionales en la preservación de ciertos espacios de América Latina, el problema del equilibrio ecológico, la importancia del discurso y la ideología que legitiman las acciones, los tópicos de la identidad nacional, la corrupción, el patriotismo oportunista y el vacío de significado.

La arquitectura urbana es el espacio de pugna de al menos dos estilos predominantes. El arquitecto Felipe Jurado, con sus edificios cúbicos y su gusto kitsch, promueve la modernidad y el design del mercado. Jesús Guardiola y la escuela de arquitectos ${ }^{3}$ defienden los valores nacionales con diseños que se inscriben en la tradición. Si el primer estilo contrasta con el perfil urbano por su desmesura (34-35), el segundo es de un nacionalismo oportunista y vacuo.

En su análisis del escenario posmoderno, Beatriz Sarlo afirma que aun los shoppings que reciclan edificios del pasado se incrustan en un vacío de memoria urbana pues allí las

\footnotetext{
${ }^{3}$ Susanne Dussel y José Morales Saravia hicieron notar, en su texto "Pirámide, axolote y crack en la arquitectura mexicana reciente”, que el personaje Jesús Guardiola constituye una parodia de arquitectos mexicanos de los años 60 como Teodoro González de León o Pedro Ramírez Vázquez. La obsesión de Jesús Guardiola por una gigantesca equis dialoga, además, según los autores citados, con "La jaula de la melancolía. Identidad y metamorfosis del mexicano" de Roger Bartra, quien define "el canon del axolote" como discurso identitario según el cual el mexicano es un ser incompleto que no alcanza nunca la adultez ni la madurez.
} 
tradiciones y la historia no son arquitectura sino decoración y souvenir (17-19). Lo mismo se puede decir del estilo de Jesús Guardiola. Despojados de su sentido práctico, los objetos tradicionales son en su casa mero adorno que cumple la función de (re)afirmar una identidad nacional que se está desmantelando: "No bastaba con haber nacido en la república de las serpientes y las aguas frescas, teníamos que parecernos a nosotros mismos, y celebrarlo a voz en cuello" (43).

El desmantelamiento de lo nacional se deja ver en distintos momentos de la novela. Me referiré especialmente a uno de ellos: las vacaciones de Mauricio en casa de Clarita Rendón, una amiga de su madre. La casa de Clarita, ubicada en el centro de la ciudad, le da a Mauricio la oportunidad de encontrarse con signos visibles de la Nación como las plazas, los monumentos, los edificios importantes. Pero nada de eso encuentra Mauricio. El centro, ese "anhelado estruendo de la ciudad” (100) resulta, al final, un espacio “decrépito y abigarrado” (105), escenario para el espectáculo mediático y el simulacro de los monumentos como mercancías. La televisión "desafiaba al pueblo mexicano a acostarse durante un mes en el aparador de una mueblería” (104). Bello Durmiente, el concursante, es el anti-gladiador de una patria (mediática) que da circo. Los monumentos, por su parte, restringen su presencia al simulacro permitido por la tienda de trofeos, "La copa de bronce”, “una región de triunfos asequibles” (117). El mercado se apropia no sólo de la cuestión de la autenticidad sino incluso de los símbolos nacionales.

Junto a eso, Mauricio es testigo de la ceremonia de la bandera. La narración habla por sí misma. Cito:

\footnotetext{
Vimos a un batallón de uniformes desteñidos doblar la tela con mucho cuidado. El aire vibró con una trompeta de hojalata y una voz quebrada hizo volar a tres palomas. El acto sugería un país pequeño, recién liberado, que aún no encontraba la forma de entusiasmarse a sí mismo. (117)
}

Otros bastiones de lo nacional que también aparecen aquí destartalados son: la ley, con una policía y una justicia corruptas; la escuela, que no logra formar a Mauricio en ninguna identidad estable; el ejército, convertido en moda juvenil con Friendly Fire; la religión, entregada a los vaivenes de la ideología política o las conveniencias familiares.

Ya no en lo arquitectónico sino en el arte está la otra vertiente de esta caída, el exotismo. En Materia dispuesta, el teatro de Ferreira es quizá el mejor ejemplo de esto. Para hacer una gira internacional de su obra Abraxas, los actores deben parecer mexicanos más que serlo, por lo cual se someten a infinitas sesiones de baños infrarrojos que los hagan “suficientemente latinos” (283).

No es menor que la obra del sincrético Ferreira elija a Crystalda como protagonista. Bailarina porno convertida de la noche a la mañana en actriz, Crystalda será, para la mirada extranjera de Lucien, "la comicidad de la era plástica/un adorable bibelot deconstruido/ una oxigenada diosa africana/la definitiva negra blanca/King Kong y la rubia en un solo cuerpo/el triunfo del sujeto sin referente" (255).

Sin referentes ni identidades fijas, la trayectoria del personaje es el contratexto de la Bildungsroman tradicional. Un contrasello inserto en una ciudad-Nación que es ahora puro acontecimiento y espectáculo. Ciudad de México, como espacio caótico y fracturado, 
sólo puede motivar una búsqueda del simulacro posmoderno, el de un cielo artificial, la inversión celeste y la imagen de las estrellas en una cartografía urbana.

\section{BiBLIOGRAFíA}

Deleuze, Gilles. La lógica del sentido [1969] Miguel Morey, trad. Barcelona: Piados Ibérica, 1989.

Dussel, Susanne y José Morales Saravia. "Pirámide, axolote y crack en la arquitectura mexicana reciente”. http://www.mexartes-berlin.de/esp/04/dussel-morales.html

García Canal, María Inés. “Espacio y diferenciación de género (Hacia la configuración de heterotopías del placer”). Debate feminista 17 (abril 1998): 47-57.

García Canclini, Néstor. Culturas híbridas. Estrategias para entrary salir de la modernidad. México, D.F.: Grijalbo, 1990. Globalización imaginada. Buenos Aires: Piados, 1999.

García Castillo, Jesús Eduardo. “Alegorías de tiempo y espacio en Materia dispuesta y El miedo a los animales”. Colmena 40. http://www.uaemex.mx/plin/colmena/ Colmena40/Aguijon/Jesus.html

González Rodríguez, Sergio. "La ciudad de México y la cultura urbana”. México a fines de siglo. José Joaquín Blanco y José Woldenberg, eds. México DF: Fondo de Cultura Económica, 1993. 235-266.

Hardt, Michael y Antonio Negri. Imperio [2000] Buenos Aires: Paidós, 2002.

Jameson, Frederic. El posmodernismo o la lógica cultural del capitalismo avanzado [1984] Barcelona: Paidós Ibérica, 1991.

Martín-Barbero, Jesús. De los medios a las mediaciones [1987] México: Editorial Gustavo Gili, 1991.

Ortiz, Renato. Otra territorio. Ensayos sobre el mundo contemporáneo. Carlos E. Cortés Sánchez, trad. Bogotá: Convenio Andrés Bello, 1998.

Pérgolis, Juan Carlos. Bogotá fragmentada. Cultura y espacio urbano a fines del siglo XX. Bogotá: Tercer Mundo, 1998.

Sarlo, Beatriz. Escenas de la vida posmoderna. Buenos Aires: Ariel, 1994.

Subercaseaux, Bernardo. Nación y Cultura en América Latina. Diversidad cultural y globalización. Santiago: LOM Ediciones, 2002.

Villoro, Juan. Materia dispuesta. México: Alfaguara, 1997.

“Chiapas: el regreso de los intocables”, "Los días robados: cielo artificial”, “Mexicamérica: la frontera de los ilegales”, http://sololiteratura.com/ villoroarticulos.htm

"La realidad no tiene obligación de parecer verosímil”, “Mudarse para mejorarse”, http://sololiteratura.com/villoromiscelanea.htm “Entrevista con Juan Villoro”. Cuadernos Hispanoamericanos 561 (marzo 1997): 119-24. 
